\title{
Terapia Celular no Tratamento do Infarto Agudo do Miocárdio
}

\author{
Franca Stedile Angeli ${ }^{1}$, Edie Mello de Oliveira ${ }^{1,2}$
}

\section{RESUMO}

Neste artigo, os autores abordam os conceitos e evidências atualmente disponíveis sobre a terapia celular no tratamento de pacientes pós-infarto agudo do miocárdio. Os tipos celulares potencialmente candidatos ao uso clínico são enfatizados, considerando-se as vias de administração e as perspectivas futuras.

DESCRITORES: Terapia tissular. Infarto do miocárdio, terapia. Transplante de células-tronco.

A pesar dos significativos avanços terapêuticos voltados ao tratamento das doenças cardiovasculares, a doença arterial coronariana (DAC) continua sendo a principal causa de mortalidade em países industrializados. O infarto agudo do miocárdio (IAM) está associado a elevada morbimortalidade ${ }^{1}$, tanto na sua fase aguda como na sua fase tardia, quando do desenvolvimento de quadros de cardiomiopatia isquêmica crônica e insuficiência ventricular.

Nos últimos anos, a medicina cardiovascular passou por uma das suas mais extraordinárias revoluções: a explosão de estudos pré-clínicos e clínicos suportando a hipótese de que o tecido cardíaco lesado poderia ser reparado com a administração de células-tronco e da conseqüente formação de novos vasos e miócitos. Apesar da incerteza em relação ao mecanismo pelo qual a terapia celular melhora a função cardíaca e regenera sua anatomia, a tradução dos achados obtidos em laboratório para o cenário clínico vem ocorrendo em ritmo cada vez mais acelerado ${ }^{2}$. Um número expressivo de pequenos estudos, na sua maioria não randomizados, reportaram a melhora da perfusão e função

\footnotetext{
1 Department of Medicine, Cardiology Division - University of California San Francisco.

2 Instituto do Coração da Serra Gaúcha - Caxias do Sul, Brasil. Correspondência: Franca Stedile Angeli. University of California, San Francisco. Department of Medicine-Cardiology 505 Parnassus Avenue, S1480C San Francisco CA 94143-0124 e-mail: fangeli@medicine.ucsf.edu

Recebido em: 19/04/2006 - Aceito em: 15/03/2007
}

SUMMARY

Cell Therapy in the Treatment of Acute Myocardial Infarction

In this article, the authors discuss the concepts and available current evidence about cell therapy in the treatment of patients with acute myocardial infarction. The cell types that are potential candidates for clinical use are detailed as are the administration routes and future perspectives.

DESCRIPTORS: Tissue therapy. Myocardial infarction, therapy. Stem cell transplantation.

cardíaca após terapia com diferentes tipos celulares em pacientes com $\mathrm{IAM}^{2}$. Apenas mais recentemente, estudos randomizados envolvendo um maior número de pacientes começaram a ter seus resultados disponibilizados na literatura. A heterogeneidade dos resultados nos estudos publicados até o presente momento ampliou os questionamentos sobre a efetividade e metodologia utilizada na geração destes dados $^{3-5}$.

Independente das evidências atualmente disponíveis, é fundamental que se enfatize que muitas ainda são as perguntas a serem respondidas antes que a terapia celular possa ser plenamente compreendida e, só então, aceita ou descartada como opção terapêutica. Pontos relevantes a serem abordados, dentro deste cenário, correlacionam-se com a identificação da célula ou produto ideal, sua posologia, a melhor via e o momento temporal para sua administração.

Nesta breve revisão, abordaremos os conceitos e evidências atualmente disponíveis sobre a terapia celular no tratamento de pacientes pós-infarto agudo do miocárdio. Por motivos metodológicos, optamos por uma abordagem baseada nos tipos celulares potencialmente candidatos ao uso clínico.

\section{Terapia celular no IAM em 2007: até onde chegamos}

Células-tronco podem ser definidas como células que possuem capacidade clonogênica e de auto-renovação e, ainda, que podem diferenciar-se em múlti- 
plas linhagens celulares ${ }^{6}$. Apesar da maioria dos estudos clínicos no tratamento do IAM, publicados até o presente momento, ter sido realizada com células-tronco provenientes da medula óssea ou, em menor número, células derivadas do músculo esquelético, outras classes celulares vêm sendo igualmente investigadas. Várias são as estratégias em estudo e incluem: a) isolados celulares autólogos primários; b) células derivadas de linhas celulares estabelecidas; c) células-tronco específicas, incluindo células da medula óssea, células mesenquimais, células provenientes do sangue de cordão umbilical, células embrionárias, e produtos provenientes de células, tecidos e órgãos geneticamente modificados ${ }^{7,8}$.

No que tange a terapia celular envolvendo células embrionárias, muito ainda está por ser definido. Estas células, inicialmente isoladas em $\operatorname{ratos}^{9} \mathrm{e}$, mais recentemente, em humanos ${ }^{10}$, são caracterizadas por sua pluripotencialidade, podendo ser induzidas à diferenciação em agregados celulares compostos pelas três linhas germinativas primárias. Esta mesma característica, contudo, associa-se a um elevado potencial oncogênico e arritmogênico, sendo um fator estimulante e, ao mesmo tempo, limitante ao seu uso clínico ${ }^{11}$. Até o presente momento, desconhecemos dados fidedignos envolvendo o uso de células embrionárias no tratamento de pacientes com IAM.

Em um segundo grande grupo, estão alocadas as chamadas células-tronco adultas. Como característica comum, estas células possuem a capacidade de manutenção, regeneração e reposição de células terminalmente diferenciadas dentro do seu tecido específico em resposta a estímulos fisiológicos (turnover celular) ou patológicos (lesão celular) ${ }^{12}$. Mais recentemente, estudos vêm demonstrando que células-tronco adultas também podem gerar células diferenciadas de outras linhas celulares, um processo denominado "desenvolvimento de plasticidade ${ }^{\prime 13}$.

No âmbito da pesquisa clínica cardiovascular, os maiores progressos com o uso de células-tronco adultas para o transplante celular no infarto agudo do miocárdio foram descritos com o uso de células-tronco hematopoiéticas, células-tronco mesenquimais e células progenitoras endoteliais.

Várias preparações de células-tronco originárias do tecido hematopoiético vêm sendo utilizadas in vivo, incluindo: células não selecionadas oriundas da medula óssea, células-tronco hematopoiéticas purificadas e células hematopoiéticas isoladas tanto da medula óssea como do sangue periférico. Como o tecido hematopoiético, tanto da medula óssea como do sangue periférico, é constituído por uma população heterogênea de células-tronco, incluindo outros tipos celulares que não o hematopoiético, as diferenças em termos de resultados reportados na literatura podem ser simplesmente originárias das diferenças em relação à fonte e à preparação das células-tronco em questão (Tabela 1). Mais do que isso, é importante que o leitor se atenha ao fato de que não necessariamente célulastronco originárias do tecido hematopoiético sejam conceitualmente e funcionalmente células-tronco hematopoiéticas.

Cabe lembrar ainda que as células hematopoiéticas e endoteliais compartilham um precursor comum e, desta forma, apresentam marcadores celulares similares (Scl1/Tal1; CD31, CD34, VE-cadherin e Tie-2) ${ }^{20}$. Tal similaridade torna sua diferenciação extremamente difícil. Assim, dentro do conhecimento científico atual, é impossível diferenciar uma célula progenitora endotelial imatura de uma célula-tronco hematopoiética primitiva. Quando da sua entrada na circulação sangüínea, é que as mesmas passam por um processo de diferenciação e a presença de diferentes marcadores celulares possibilita sua individualização ${ }^{21,22}$.

No que tange o uso clínico de células progenitoras hematopoiéticas no tratamento do IAM, parte significativa dos resultados clínicos publicados nesta área utilizou a medula óssea como fonte celular (Tabela 1). O processo de separação pelo gradiente de Ficoll foi o método mais amplamente empregado, permitindo a seleção da fração mononuclear do aspirado. Esta fração contém células-tronco hematopoiéticas, progenitoras endoteliais e, em menor número, células-tronco mesenquimais.

Células mononucleares foram administradas via intracoronária e a segurança desta terapia foi demonstrada na maior parte dos estudos listados (Tabela 1). Bartunek et al. ${ }^{17}$, contudo, demonstraram que a administração de células progenitoras da medula óssea CD133 enriquecidas esteve associada a um aumento de eventos coronarianos. Por se tratar de um estudo não randomizado, envolvendo um número pequeno de pacientes, a força de tais dados não é suficiente para contradizer o somatório dos resultados dos demais estudos.

No que tange a efetividade, a variabilidade nos achados reportados pode ser, em parte, explicada pela variabilidade na logística de tratamento e grupos tratados nos diferentes estudos envolvendo pacientes com infarto agudo do miocárdio. Mesmo apresentando efeito positivo em termos de recuperação da função cardíaca na maioria dos grupos tratados, a melhora em termos de fração de ejeção não foi significativa em todos os estudos $^{3-5,19}$. O estudo de Jansenns et al. ${ }^{5}$ torna clara a necessidade de padronização de condutas na comparação de resultados. Neste elegante estudo randomizado envolvendo 67 pacientes, o grupo de pacientes tratados nas 24 horas após o início do IAM não apresentou melhora estatisticamente significativa em termos de fração de ejeção. Contudo, efeito positivo em termos de remodelamento foi demonstrado no grupo tratado. Dois pontos cruciais a serem discutidos neste trabalho são: 1) administração precoce do tratamento; 2) critérios de seleção dos pacientes tratados.

O tempo ideal para administração de células-tronco após um evento agudo está por ser definido. Evidên- 
TABELA 1

Células-tronco adultas no tratamento do infarto agudo do miocárdio (IAM): estudos clínicos

\begin{tabular}{|c|c|c|c|c|c|c|c|}
\hline Estudo & {$[\mathrm{n}]$} & $\begin{array}{l}\text { Tipo e fonte } \\
\text { celular }\end{array}$ & Dose & $\begin{array}{c}\text { Método de } \\
\text { administração }\end{array}$ & $\begin{array}{c}\text { Tempo } \\
\text { após IAM }\end{array}$ & $\begin{array}{c}\text { Melhora } \\
\text { Terapêutica }\end{array}$ & Manutenção \\
\hline \multicolumn{8}{|c|}{ NÃO-RANDOMIZADOS } \\
\hline Strauer et al. ${ }^{14}$ & $\begin{array}{c}10 \text { casos, } \\
10 \text { controles }\end{array}$ & $\begin{array}{c}\text { MNC autólogos, } \\
\text { medula óssea }\end{array}$ & $1,8 \times 10^{7}$ & Intracoronária & 5-9 dias & $\begin{array}{c}\text { Contratilidade } \\
\text { regional*, } \\
\text { Perfusão*, } \\
\downarrow \text { Tamanho } \\
\text { do infarto }\end{array}$ & $\begin{array}{c}\text { FEVE global, } \\
\text { VDFVE* }\end{array}$ \\
\hline TOPCARE-AMI ${ }^{15}$ & $\begin{array}{c}29 \mathrm{MNC}, \\
30 \mathrm{CPC}, \\
11 \text { controles }\end{array}$ & $\begin{array}{l}\text { MNC, } \\
\text { CPC }\end{array}$ & $\begin{array}{l}2,1 \pm 0,8 \times 10^{8} \\
1,6 \pm 1,2 \times 10^{7}\end{array}$ & Intracoronária & $5 \pm 2$ dias & $\begin{array}{l}\text { Contratilidade } \\
\text { regional*, FEVE } \\
\text { global }(8 \%)^{*} \text {, } \\
\downarrow \text { Tamanho do } \\
\text { infarto*, Fluxo } \\
\text { colateral* }^{*}\end{array}$ & $\begin{array}{l}\text { VDFVE* } \\
\text { Não houve } \\
\text { diferença } \\
\text { entre os tipos } \\
\text { celulares }\end{array}$ \\
\hline $\begin{array}{l}\text { Fernandez- } \\
\text { Aviles et al. }{ }^{16}\end{array}$ & $\begin{array}{c}20 \text { casos, } \\
13 \text { controles }\end{array}$ & MNC & $7,8 \pm 4,1 \times 10^{7}$ & Intracoronária & $14 \pm 6$ dias & & VDFVE* \\
\hline Bartunek et al. ${ }^{17}$ & $\begin{array}{c}19 \text { casos, } \\
16 \text { controles }\end{array}$ & $\begin{array}{c}\text { CD 133+ } \\
\text { (medula óssea) }\end{array}$ & $12,6 \pm 2,2 \times 10^{6}$ & Intracoronária & $\begin{array}{l}11,6 \pm 1,4 \\
\text { dias }\end{array}$ & $\begin{array}{c}\text { Melhora } \\
\text { perfusão, } \\
\text { Redução defeito } \\
\text { perfusão, FEVE } \\
\text { global }(7 \%)\end{array}$ & \\
\hline \multicolumn{8}{|c|}{ ESTUDOS RANDOMIZADOS } \\
\hline BOOST $^{3}$ & $\begin{array}{c}30 \text { casos, } \\
30 \text { controles }\end{array}$ & $\begin{array}{c}\text { CN- medula } \\
\text { óssea }\end{array}$ & $2,5 \pm 0,9 \times 10^{10}$ & Intracoronária & $6 \pm 1$ dias & $\begin{array}{l}\text { Contratilidade } \\
\text { regional, FEVE } \\
\text { global }(6 \%)\end{array}$ & $\begin{array}{l}\text { VDFVE, } \\
\text { Tamanho } \\
\text { infarto }\end{array}$ \\
\hline Chen et al. ${ }^{18}$ & $\begin{array}{c}34 \text { casos, } \\
35 \text { controles }\end{array}$ & Mesenquimais & $4,8 \pm 6,0 \times 10^{10}$ & Intracoronária & 18 dias & $\begin{array}{c}\text { Contratilidade } \\
\text { regional, } \\
\downarrow \text { Tamanho } \\
\text { infarto, FEVE } \\
\text { global (14\% } \\
\text { acima controles), } \\
\downarrow \text { VDFVE }\end{array}$ & \\
\hline ASTAMI $^{19}$ & $\begin{array}{c}52 \text { casos, } \\
48 \text { controles }\end{array}$ & $\begin{array}{c}\text { MNC, } \\
\text { medula óssea }\end{array}$ & $\begin{array}{l}\text { Dado não } \\
\text { disponível }\end{array}$ & Intracoronária & 5-8 dias & & $\begin{array}{l}\text { FEVE, } \\
\text { Tamanho } \\
\text { infarto, } \\
\text { VDFVE }\end{array}$ \\
\hline REPAIR-AMI ${ }^{4}$ & $\begin{array}{c}101 \text { casos, } \\
103 \text { controles }\end{array}$ & $\begin{array}{c}\text { MNC, } \\
\text { medula óssea }\end{array}$ & $2,36 \pm 1,74 \times 10^{10}$ & Intracoronária & $3-6$ dias & $\begin{array}{c}\text { FEVE, previne } \\
\text { aumento volume } \\
\text { sistólico VE em } \\
4 \text { meses }\end{array}$ & \\
\hline Janssens et al..$^{5}$ & $\begin{array}{c}33 \text { casos, } \\
34 \text { controles }\end{array}$ & $\begin{array}{l}\text { CN e MNC } \\
\text { medula óssea }\end{array}$ & $\begin{array}{l}3,0 \pm 1,3 \times 10^{8} \\
1,7 \pm 0,7 \times 10^{8}\end{array}$ & Intracoronária & $\begin{array}{c}\text { Primeiras } \\
24 \text { horas }\end{array}$ & $\begin{array}{c}\downarrow \text { Tamanho } \\
\text { infarto, Melhora } \\
\text { função sistólica } \\
\text { regional }\end{array}$ & FEVE global \\
\hline
\end{tabular}

*Efeitos reportados no grupo tratamento isoladamente. $\mathrm{MNC}=$ células mononucleares; $\mathrm{CN}=$ células nucleadas; $\mathrm{FEVE}=$ fração de ejeção do ventrículo esquerdo; VDFVE= Volume diastólico final do ventrículo esquerdo.

cias sugerem que o intervalo entre o terceiro e o sétimo dia após o IAM seja o período mais propício para a administração das células-tronco ${ }^{23}$. Um segundo aspecto a ser mencionado é o fato de os autores terem incluído um grupo de pacientes de baixo-risco, cuja fração de ejeção média por ecocardiografia era $54 \%$, quando da randomização. A melhora no grupo tratado não foi estatisticamente significante, mas a fra- 
ção de ejeção de base estava preservada e melhoras estrondosas não poderiam ser esperadas neste caso.

Achado igualmente instigante é o reportado nos 18 meses de seguimento no estudo BOOST ${ }^{24}$. O tratamento com células-tronco da medula óssea é seguro e não esteve associado a eventos adversos a longo prazo. Contudo, a melhora da fração de ejeção global e regional no grupo tratado em relação ao grupo controle foi mantida nos 18 meses de seguimento. A análise dos dados sugere que a terapia com células-tronco pode estar associada a uma recuperação acelerada da função ventricular, sendo a melhora equiparável à apresentada no grupo controle aos 18 meses. O número limitado de pacientes (n:60) não permitiu que os autores estratificassem os resultados por diferentes características da amostra. Assim, duas hipóteses são levantadas na discussão deste importante estudo: 1) o efeito da terapia celular é transitório e não está associado a significativo reparo estrutural; 2) a terapia celular exerce efeito positivo no processo regenerativo endógeno, acelerando este evento; 3) a posologia de administração do produto celular é inadequada ao objetivo proposto.

O estudo REPAIR-AMI ${ }^{25}$, por sua vez, demonstrou que a administração de células progenitoras da medula óssea esteve associada a melhora da função ventricular no seguimento de quatro meses. Mais importante, demonstrou que pacientes com fração de ejeção inferior ao valor médio de $48,9 \%$ foram os maiores beneficiados do tratamento. No seguimento de um ano, a terapia esteve associada a redução de eventos cardíacos e morte.

Respostas a estas perguntas só poderão ser obtidas com a publicação dos resultados de outros estudos em andamento. $\mathrm{O}$ estudo brasileiro $\mathrm{MiHeart}{ }^{26}$ e o estudo BOOST-2 deverão trazer novos dados em relação aos efeitos em longo prazo da injeção intracoronariana de células-tronco na fração de ejeção de pacientes pósIAM. Tais resultados reforçam, mais uma vez, a idéia de que devamos concentrar esforços na definição do grupo a ser tratado, intervalo de tempo ideal para o tratamento, bem como produto e posologia de administração.

Poucos são os estudos clínicos que avaliaram o uso isolado das células progenitoras endoteliais no tratamento de pacientes pós-IAM. As mesmas podem ser isoladas na medula óssea ou no sangue periférico circulante e demonstraram ser capazes de contribuir na revascularização de tecidos lesados. No estudo TOPCARE-AMI, a terapia com células progenitoras endoteliais foi segura e esteve associada à melhora da função e da perfusão miocárdica (Tabela 1) ${ }^{15}$. Apesar de encorajadores, os resultados deste estudo devem ser encarados com cautela por se tratar de um estudo não-randomizado.

Por fim, as chamadas células-tronco mesenquimais podem ser encontradas na medula óssea, tecido mus- cular, pele e tecido adiposo, sendo caracterizadas pelo seu potencial de diferenciação em células musculares, fibroblastos, osso, tendão, ligamento e tecido adiposo ${ }^{27,28}$. Apesar de representarem menos de $0,01 \%$ das células nucleadas da medula óssea, estas células são facilmente expandidas in vitro e têm a capacidade de diferenciação em cardiomiócitos em meios de cultura apropria$\operatorname{dos}^{26,29}$. Da mesma forma, quando injetadas em tecido miocárdio adulto normal, as mesmas poderiam se diferenciar em células com fenótipo de cardiomiócito ${ }^{30}$. O estudo clínico conduzido por Chen et al. ${ }^{18}$ demonstrou que a injeção de células-tronco mesenquimais esteve associada à melhora da função ventricular. Vários novos estudos vêm sendo realizados na tentativa de comprovar a utilidade das células-tronco mesenquimais no tratamento de doenças cardiovasculares. Cabe lembrar, contudo, que a necessidade de cultura para obtenção de número adequado de células, bem como as características morfológicas desta célula, podem ser um fator limitante à sua administração intracoronariana. Em estudo pré-clínico, Vulliet et al. ${ }^{31}$ demonstraram a presença de oclusão da microcirculação após a infusão de células mesenquimais, associando o tamanho das células ao risco de obstrução de fluxo.

\section{Vias de administração}

Grande parte do trabalhos clínicos voltados à avaliação da terapia com células-tronco foi direcionada ao tratamento de infarto agudo do miocárdio (IAM) 3,15. A injeção intracoronariana tem sido a técnica mais amplamente utilizada no tratamento destes pacientes e caracteriza-se por ser uma técnica facilmente executável, não requerendo investimento adicional em equipamento ou tecnologia de imagem. As desvantagens dessa técnica estão associadas à necessidade de patência da árvore coronariana, sendo que a efetividade da administração e distribuição das células no tecido lesado depende da preservação do fluxo na microcirculação coronariana, nem sempre presente neste cenário. Paralelamente, o próprio produto a ser administrado pode ser causa de tromboembolismo, potencialmente gerando uma segunda lesão isquêmica em um miocárdio infartado. Relatos envolvendo a administração de células de maior diâmetro, como as progenitoras mesenquimais, esqueleto-mieloblastos ou grandes volumes de células, sugerem tal risco (Figura 1$)^{31}$.

A via de administração sistêmica, por sua vez, está alicerçada na idéia de que as células-tronco são atraídas for fatores quimiotáxicos para os tecidos injuriados (do inglês homing). Os resultados clínicos com o uso desta técnica de forma isolada são menos encorajadores $^{33}$. Contudo, os mesmos serviram como prova conceitual da capacidade de mobilização periférica de células-tronco, bem como serviram como modelo para o desenvolvimento de métodos alternativos de tratamento celular.

Métodos alternativos de administração de produtos celulares na fase aguda ou subaguda do infarto agudo 


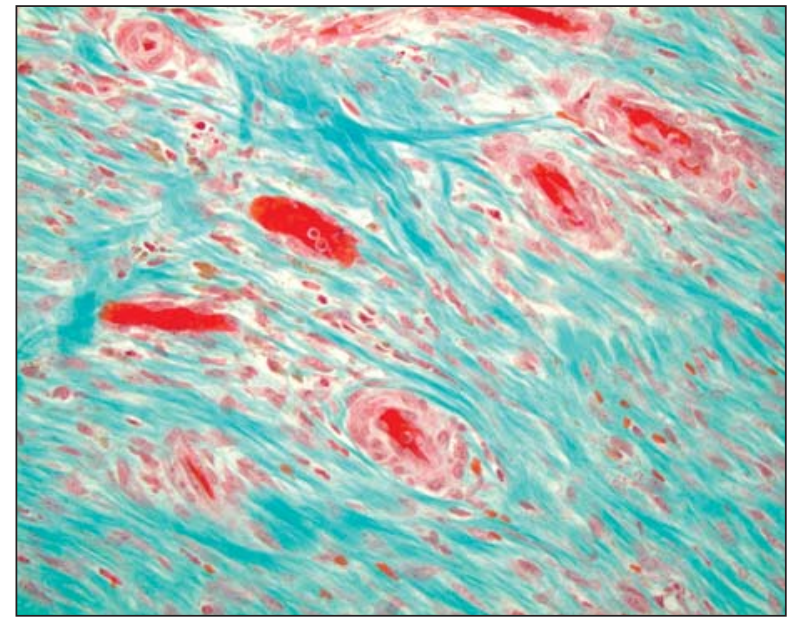

Figura 1 - Coloração em tricromo em modelo canino, mostrando que, após uma injeção intracoronária de células mesenquimais, encontramos uma quantidade significativa de agregados celulares oclusivos em microcirculação ${ }^{32}$.

do miocárdio vêm sendo testados. A injeção a céu aberto como terapia adjunta à cirurgia de revascularização é uma proposta viável, mas que atende a um grupo seleto de pacientes com indicação de revascularização cirúrgica imediatamente após um evento isquêmico agudo ${ }^{34}$. A via transendocárdica, por sua vez, foi inicialmente reservada para o tratamento de pacientes isquêmicos crônico, pelo risco de perfuração e desenvolvimento de arritmias ${ }^{35}$. Contudo, estudos pré-clínicos vêm sendo realizados no sentido de comprovar a segurança destes procedimentos e abrir a possibilidade de seu uso no tratamento de eventos isquêmicos agudos.

\section{Perspectivas futuras}

Várias são as etapas a serem ultrapassadas até que a terapia celular no tratamento do IAM seja considerada passível de uso clínico. Um dos pontos a serem trabalhados está associado à disponibilidade e à facilidade de obtenção de células-tronco. A medula óssea humana tem uma limitada quantidade de células progenitoras hematopoiéticas (entre 1 e $2 \%$ ) e mesenquimais $(<0,05 \%)$. Paralelamente, a própria identificação dos marcadores de superfície ou de formas alternativas de identificação celular necessita de aprimoramento.

Apesar da plasticidade e grande potencial para proliferação e diferenciação demonstrado pelas célulastronco in vitro e em certos modelos in vivo, existe uma ampla variabilidade entre os diferentes tipos celulares ou mesmo entre os produtos oriundos do aspirado de medula óssea. Além da necessidade de reprodução destes resultados em estudos clínicos, a uniformização da classificação e caracterização das células-tronco e células progenitoras é um objetivo ainda a ser alcançado. Em paralelo, a identificação de condições de cultura que possibilitem a propagação de células-tronco de forma segura poderia corrigir parte destas diferenças.
Outra perspectiva futura, já em fase avançada de experimentação, é a engenharia de tecidos ${ }^{36,37}$. O implante de células-tronco em estruturas biodegradáveis demonstrou ser um método plausível e associado a resultados positivos in vitro ${ }^{38}$. Alternativas envolvendo a combinação de cardiomioplastia celular com terapia genética também vêm sendo testadas com sucesso em modelos experimentais in vivo ${ }^{39}$.

Assim, muitas são as questões a serem respondidas. Qual é a duração do efeito após adesão das células? Qual a melhor posologia, momento temporal e distribuição tecidual de células transplantadas em tecidos hipoperfundidos? O novo cardiomiócito terá contração sincronizada na área infartada ou terá efeito arritmogênico? A plasticidade, observada nas célulastronco, é resultado de fusão celular? Quanto será possível transferir os dados pré-clínicos para estudos humanos?

A despeito desses desafios, a terapia celular na doença cardiovascular é hoje uma realidade que já não pode ser ignorada. Mesmo que ainda necessitando refinamentos técnicos, padronização dos protocolos e validações científicas de vários dos achados aqui reportados, tudo leva a crer que a mesma contribuirá direta ou indiretamente no tratamento de pacientes com doença cardíaca aguda (IAM). Para tanto, é importante que critérios éticos e científicos sejam respeitados nesta caminhada. Etapas fundamentais na formulação de hipóteses e validação das mesmas não podem, de forma alguma, ser perpassadas. Apesar de longo, o caminho a ser percorrido é gratificante e tem modificado nosso entendimento sobre a fisiopatologia das doenças cardiovasculares. No início, tratávamos órgãos, depois passamos a tratar tecidos, hoje tentamos tratar pacientes no nível celular e genético. $E$, neste aspecto, mais uma vez, vemos a Cardiologia avançando com passos largos, dando um grande exemplo de amplitude de atuação e transposição de fronteiras.

\section{REFERÊNCIAS BIBLIOGRÁFICAS}

1. Pasternak RC, Criqui MH, Benjamin EJ, Fowkes FG, Isselbacher EM, McCullough PA, et al. Atherosclerotic Vascular Disease Conference: Writing Group I: epidemiology. Circulation. 2004;109(21):2605-12.

2. Wollert KC, Drexler H. Clinical applications of stem cells for the heart. Cir Res. 2005;96(2):151-63.

3. Wollert KC, Meyer GP, Lotz J, Ringes-Lichtenberg S, Lippolt $\mathrm{P}$, Breidenbach $\mathrm{C}$, et al. Intracoronary autologous bonemarrow cell transfer after myocardial infarction: the BOOST randomised controlled clinical trial. Lancet. 2004;364(9429): $141-8$.

4. Schachinger V, Erbs S, Elsasser A. Intracoronary infusion of bone marrow-derived progenitor cells in acute myocardial infarction: a randomized, double-blind, placebo-controlled multicenter trial (REPAIR-AMI). Circulation. 2005;112:3362.

5. Janssens S, Dubois C, Bogaert J, Theunissen K, Deroose C, Desmet W, et al. Autologous bone marrow-derived stemcell transfer in patients with ST-segment elevation myocardial infarction: double-blind, randomised controlled trial. Lancet. 2006;367(9505):113-21. 
6. Weissman IL. Stem cells: units of development, units of regeneration, and units in evolution. Cell. 2000;100(1):157-68.

7. Asahara T, Kalka C, Isner JM. Stem cell therapy and gene transfer for regeneration. Gene Ther. 2000;7(6):451-7.

8. Fodor WL. Tissue engineering and cell based therapies, from the bench to the clinic: the potential to replace, repair and regenerate. Reprod Biol Endocrinol. 2003;1:102.

9. Evans MJ, Kaufman MH. Establishment in culture of pluripotential cells from mouse embryos. Nature. 1981;292(5819): 154-6.

10. Thomson JA, Itskovitz-Eldor J, Shapiro SS, Waknitz MA, Swiergiel JJ, Marshall VS, et al. Embryonic stem cell lines derived from human blastocysts. Science. 1998;282(5391): 1145-7.

11. Cibelli JB, Grant KA, Chapman KB, Cunniff K, Worst T, Green $\mathrm{HL}$, et al. Parthenogenetic stem cells in nonhuman primates. Science. 2002;295(5556):819.

12. Slack JM. Stem cells in epithelial tissues. Science. 2000;287 (5457):1431-3.

13. Poulsom R, Alison MR, Forbes SJ, Wright NA. Adult stem cell plasticity. J Pathol. 2002;197(4):441-56.

14. Strauer BE, Brehm M, Zeus T, Kostering M, Hernandez A, Sorg RV, et al. Repair of infarcted myocardium by autologous intracoronary mononuclear bone marrow cell transplantation in humans. Circulation. 2002;106(15):1913-8.

15. Fernandez-Aviles F, San Roman JA, Garcia-Frade J, Fernandez $M E$, Penarrubia MJ, de la Fuente $L$, et al. Experimental and clinical regenerative capability of human bone marrow cells after myocardial infarction. Circ Res. 2004;95(7):742-8.

16. Rumpold H, Wolf D, Koeck R, Gunsilius E. Endothelial progenitor cells: a source for therapeutic vasculogenesis? J Cell Mol Med. 2004;8(4):509-18.

17. Iwami Y, Masuda H, Asahara T. Endothelial progenitor cells: past, state of art, and future. J Cell Mol Med. 2004;8(4): 488-97.

18. Yin AH, Miraglia S, Zanjani ED, Almeida-Porada G, Ogawa $M$, Leary AG, et al. AC133, a novel marker for human hematopoietic stem and progenitor cells. Blood 1997;90(12): 5002-12.

19. Bartunek J, Vanderheyden M, Vandekerckhove B, Mansour S, De Bruyne B, De Bondt P, et al. Intracoronary injection of CD 133-positive enriched bone marrow progenitor cells promotes cardiac recovery after recent myocardial infarction: feasibility and safety. Circulation. 2005;112(9 Suppl):1178-83.

20. Lunde K, Solheim S, Aakhus S, Arnesen H, Abdelnoor M, Egeland $\mathrm{T}$, et al. Intracoronary injections of mononuclear bone marrow cells in acute myocardial infarction. $N$ Engl J Med 2006;355(12):1199-209.

21. Bartunek J, Wijns W, Heyndrickx GR, Vanderheyden M. Timing of intracoronary bone-marrow-derived stem cell transplantation after ST-elevation myocardial infarction. Nat Clin Pract Cardiovasc Med. 2006;3(Suppl 1):S52-6.

22. Meyer GP, Wollert KC, Lotz J, Steffens J, Lippolt P, Fichtner $\mathrm{S}$, et al. Intracoronary bone marrow cell transfer after myocardial infarction: eighteen months' follow-up data from the randomized, controlled BOOST (Bone marrOw transfer to enhance ST-elevation infarct regeneration) trial. Circulation. 2006;113(10):1272-94.

23. Schachinger V, Erbs S, Elsasser A, Haberbosch W, Hambrecht $\mathrm{R}$, Holschermann $\mathrm{H}$, et al. Intracoronary bone marrow- derived progenitor cells in acute myocardial infarction. N Engl J Med. 2006;335(12):1210-21.

24. Tura BR, Martino HF, Gowdak LH, Santos RR, Dohmann $\mathrm{HF}$, Krieger JE, et al. Multicenter randomized trial of cell therapy in cardiopathies - MiHeart Study. Trials. 2007;8:2.

25. Assmus B, Schachinger $V$, Teupe $C$, Britten M, Lehmann R, Dobert N, et al. Transplantation of Progenitor Cells and Regeneration Enhancement in Acute Myocardial Infarction (TOPCARE-AMI). Circulation. 2002;106(24):3009-17.

26. Pittenger MF, Mackay AM, Beck SC, Jaiswal RK, Douglas R, Mosca JD, et al. Multilineage potential of adult human mesenchymal stem cells. Science. 1999;284(5411):143-7.

27. Caplan AI. Review: mesenchymal stem cells: cell-based reconstructive therapy in orthopedics. Tissue Eng. 2005;11(78):1198-211.

28. Makino S, Fukuda K, Miyoshi S, Konishi F, Kodama H, Pan J, et al. Cardiomyocytes can be generated from marrow stromal cells in vitro. J Clin Invest. 1999;103(5):697-705.

29. Toma C, Pittenger MF, Cahill KS, Byrne BJ, Kessler PD. Human mesenchymal stem cells differentiate to a cardiomyocyte phenotype in the adult murine heart. Circulation. 2002;105 (1):93-8.

30. Chen SL, Fang WW, Ye F, Liu YH, Qian J, Shan SJ, et al. Effect on left ventricular function of intracoronary transplantation of autologous bone marrow mesenchymal stem cell in patients with acute myocardial infarction. Am J Cardiol. 2004;94(1):92-5.

31. Vulliet PR, Greeley M, Halloran SM, MacDonald KA, Kittleson MD. Intra-coronary arterial injection of mesenchymal stromal cells and microinfarction in dogs. Lancet. 2004;363(9411): 783-4.

32. Perin EC, Silva GS, Saad J, et al. Comparison between intracoronary infusion and direct transendocardial injection of mesenchymal stem cells in a dog acute ischemia model. J Am Coll Cardiol. 2005;45(3):435.

33. Barbash IM, Chouraqui $\mathrm{P}$, Baron J, Feinberg MS, Etzion S, Tessone A, et al. Systemic delivery of bone marrow-derived mesenchymal stem cells to the infarcted myocardium: feasibility, cell migration, and body distribution. Circulation. 2003;108(7):863-8.

34. Menasche P, Hagege AA, Scorsin M, Pouzet B, Desnos $M$, Duboc $D$, et al. Myoblast transplantation for heart failure. Lancet. 2001;357(9252):279-80.

35. Perin EC, Lopez J. Methods of stem cell delivery in cardiac diseases. Nat Clin Pract Cardiovasc Med. 2006;3(Suppl 1): S110-3.

36. Christman KL, Lee RJ. Biomaterials for the treatment of myocardial infarction. J Am Coll Cardiol. 2006;48(5):907-13.

37. Leor J, Amsalem Y, Cohen S. Cells, scaffolds, and molecules for myocardial tissue engineering. Pharmacol Ther. 2005; 105(2):151-63.

38. Narmoneva DA, Vukmirovic R, Davis ME, Kamm RD, Lee RT. Endothelial cells promote cardiac myocyte survival and spatial reorganization: implications for cardiac regeneration. Circulation. 2004;110(8):962-8.

39. Davis ME, Hsieh PC, Takahashi T, Song Q, Zhang S, Kamm $R D$, et al. Local myocardial insulin-like growth factor 1 (IGF-1) delivery with biotinylated peptide nanofibers improves cell therapy for myocardial infarction. Proc Natl Acad Sci USA. 2006;103(21):8155-60. 